\title{
Clinical spectrum of obstructive jaundice: a descriptive cross- sectional study
}

\author{
R. Naveena $\mathrm{MS}^{1 *}$ \\ ${ }^{1}$ Government OMANDURAR MEDICAL COLLEGE HoSPITAL, DEPARTMENT OF GENERAL SURGERY, CHENNAI, INDIA
}

\begin{abstract}
Objective. The objective of this study was to evaluate the clinical spectrum of obstructive jaundice in inflammation, stone disease, and malignancy. Methods. A descriptive observational study was done among 50 patients with the diagnosis of obstructive jaundice during the period 2012 to 2013. A detailed history and clinical examinations and radiological confirmation were done. Results. Among the participants, $74 \%$ participants had jaundice, $58 \%$ with vomiting as presenting complaints. Among benign cases, $60 \%$ were choledocholithiasis, $25 \%$ were common bile duct stricture, and $15 \%$ were choledochal cyst. Among malignant cases, $26.67 \%$ were periampullary carcinoma, $23.33 \%$ had carcinoma of the pancreas head, and $13.33 \%$ had D2 duodenal carcinoma. Conclusions. The etiology of obstructive jaundice was malignancy in the elderly male population. The most common presenting features were yellowish discoloration of skin and mucosa followed by vomiting and abdominal pain.
\end{abstract}

\section{Introduction}

Yellowish discoloration of the skin and mucous membranes is termed jaundice. This coloration occurs due to the increase in the bilirubin levels in the body. A plasma bilirubin concentration higher than $50 \mathrm{Mmol} / \mathrm{L}$ or $2-3$ $\mathrm{mg} / \mathrm{dl}$ manifests as jaundice [1]. Obstructive jaundice occurs when there is an ability to release the conjugated bilirubin into the duodenum. The causes of obstruction can be multifactorial. Some of them can be intrahepatic causes, which causes medical jaundice such as viral hepatitis, alcoholic hepatitis, cirrhosis, etc. The surgical jaundice is caused due to extrahepatic biliary obstruction caused due to choledocholithiasis, benign biliary stricture, intraoperative biliary tract injury or ligation, cholangiocarcinoma, carcinoma in the head or neck of the pancreas, primary sclerosing cholangitis, hydatid cyst compression or intra-biliary rupture, etc. [2-4]. This obstructive jaundice implies diagnostic and therapeutic challenges to the surgeon. Surgical jaundice significantly contributes to morbidity and mortality $[5,6]$. Obstructive jaundice has varied clinical presentation such as yellowish discoloration of the skin and mucous membranes, dark- colored urine, pale stools, and generalized pruritus [7]. Biochemically, it is characterized by elevated levels of serum alkaline phosphatase [8,9]. Various imaging modalities are available for the diagnosis of obstructive jaundice, such as ultrasonography, which can identify the gallstones, dilated biliary ducts, masses in the abdomen, and the level of peritoneal fluid $[3,10]$. The gold standard diagnostic test is endoscopic retrograde cholangiopancreatography (ERCP) [4,11]. ERCP can diagnose gallstones, presence of stricture in the common bile duct, any obstruction of the duct. Brush biopsy can also be taken for cytological analysis through ERCP. Computer tomography (CT) of the abdomen also plays a significant role in identifying the cause of obstructive jaundice. In spite of the advances in diagnosis and treatment modalities available, survival remains poor in malignant cases [12]. The previously available studies have discussed the clinical presentation and management of obstructive jaundice $[9,10,13,14]$. But there are gaps in the literature on the clinical spectrum in the present study area. Hence, this study was planned to fill in the existing lacunae. There is a wide variety of presentations of obstructive jaundice and preoperative evaluation to identify the cause is essential. 
This study was conducted with the objective to evaluate the clinical spectrum of obstructive jaundice in inflammation, stone disease, and malignancy.

\section{Materials and Methods}

A descriptive observational study was conducted at the department of general surgery, Tirunelveli Medical College, during the year 2012 to 2013. Patients admitted with features of obstructive jaundice were included as study participants. Patients aged more than 18 years with clinical features and biochemical tests suggestive of obstructive jaundice were included in the study.

Simple random sampling was done by using random number tables to select the patients. The study was approved by the institutional ethics committee. Informed written consent was obtained from all participants, and data confidentiality was maintained.

Clinically evaluation was done by examination of the mucous membranes of the mouth, palm and sole, and sclera in natural light for signs of yellowish discoloration. Cholestatic syndrome signs and symptoms related to conjugated hyperbilirubinemia were evaluated. Features suggestive of chronic malabsorption of fat-soluble vitamins (vitamins A, D, E, and $\mathrm{K}$ ) such as jaundice, dark urine, pale stools, pruritis, bruising, steatorrhea, night blindness, osteomalacia, neuromuscular weakness were also evaluated.

Biochemically, the evaluation was done by van den Bergh/diazo reaction for conjugated hyperbilirubinemia, serum bilirubin levels for elevated direct bilirubin and enzyme levels like elevated alkaline phosphatase were also recorded. Patients were evaluated by age, sex, the main complaints at the time of presentation, cause for surgical jaundice, USG finding, CT abdomen correlation, morbidity and mortality due to the disease, treatment given, morbidities following treatment, and malignancies causing obstructive jaundice.

The sample size was calculated assuming the proportion of malignant obstructive jaundice is $56.6 \%$ according to the study by Khurram Siddique et al. [14]. The other parameters considered for sample size calculation were $15 \%$ absolute precision and $95 \%$ confidence level. The sample size obtained according to the above parameters was 42 . Taking into account a non-participation rate of about $10 \%$, eight other subjects were added to the sample size. Therefore, the final size was obtained for the sample of 50 participants.

\section{Statistical Methods}

Etiology, treatment complications, ultrasonographic features, etc., were considered as primary outcome variables. Treatment modalities and other demographic parameters were considered as primary explanatory variables.
Descriptive analysis was carried out by mean and standard deviation for quantitative variables, frequency, and proportion for categorical variables. Non-normally distributed quantitative variables were summarized by the median and interquartile range (IQR). Data was also represented using appropriate diagrams like bar diagrams and pie diagrams.

\section{Results}

A total of 50 subjects were included in the final analysis.

The majority of $74 \%$ participants had jaundice, and others had vomiting, abdominal pain, loss of appetite, abdominal distension, and itching as main complaints. Among the study population, 20 participants (40\%) had benign, and $60 \%$ had malignant etiology for obstructive jaundice (Table 1 and Figure 1).

Table 1. Summary of the demographic parameters $(\mathrm{N}=50)$

\begin{tabular}{|l|c|}
\hline \multicolumn{1}{|c|}{ Parameter } & Summary \\
\hline Age group & \\
\hline$<30$ years & $4(8 \%)$ \\
\hline 31 to 50 years & $16(32 \%)$ \\
\hline 51 to 70 years & $23(46 \%)$ \\
\hline$>71$ years and above & $7(14 \%)$ \\
\hline Gender & \\
\hline Male & $34(68 \%)$ \\
\hline Female & $16(32 \%)$ \\
\hline
\end{tabular}

Etiology

\begin{tabular}{|c|c|}
\hline Benign & $20(40 \%)$ \\
\hline$\circ$ Choledocholithiasis & $12(60 \%)$ \\
\hline$\circ$ CBD stricture & $5(25 \%)$ \\
\hline$\circ$ Choledochal cyst & $3(15 \%)$ \\
\hline Malignant & $\mathbf{3 0}(\mathbf{6 0} \%)$ \\
\hline$\circ$ Periampullary carcinoma & $8(26.67 \%)$ \\
\hline$\circ$ Carcinoma head of pancreas & $7(23.33 \%)$ \\
\hline$\circ$ D2 duodenal carcinoma & $4(13.33 \%)$ \\
\hline${ }^{\circ}$ Liver secondaries with porta & $3(10 \%)$ \\
\hline hepatis nodes & $3(10 \%)$ \\
\hline$\circ$ Cholangiocarcinoma & $3(10 \%)$ \\
\hline$\circ$ Gall bladder carcinoma & $2(6.67 \%)$ \\
\hline
\end{tabular}




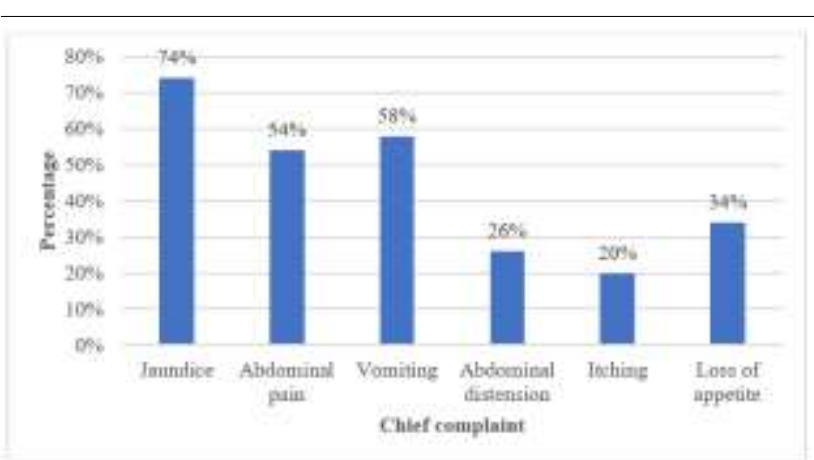

Figure 1. Bar chart of chief complaint in the study population $(\mathrm{N}=50) *$ Multiple complaints in same patients

Among the study population, 25 (50\%) participants had CBD dilation, 18 (36\%) participants had growth, and 7 (14\%) participants had stones as ultrasonographic features. Among the CT abdomen patients, the majority 11 (44\%) had lymphadenopathy, 7 (28\%) had biliary tract dilatation, generally ascites being present (Table 2).

Table 2. Summary of ultrasonographic features and CT abdomen $(\mathrm{N}=50)$

\begin{tabular}{|l|l|}
\hline Parameter & Summary \\
\hline Ultrasonographic features & \\
\hline CBD dilatation & $25(50 \%)$ \\
\hline Growth & $18(36 \%)$ \\
\hline Stones & $7(14 \%)$ \\
\hline CT abdomen(N=25) & \\
\hline Biliary tract dilatation & $7(28 \%)$ \\
\hline Ascites & $7(28 \%)$ \\
\hline Lymphadenopathy & $11(44 \%)$ \\
\hline
\end{tabular}

Among the people with jaundice, the majority of patients (48\%) had secondary liver conditions, followed by ascites, cachexia, anorexia, and cholangitis. Among the people who underwent the surgery, 7 (35\%) benefited from a triple bypass, $8(40 \%)$ underwent choledocholithotomy and choledochoduodenostomy, and 5 (25\%) underwent other bypass procedures (Figure 2 and Table 3 ).

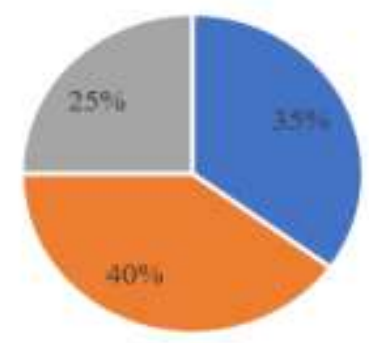

\section{- Triple bypass \\ - Choledocholithotomy and choledochoduodenostomy = Other bypass procedures}

Figure 2. pie chart of type of surgery in the study population $(\mathrm{N}=20)$
Table 3. Summary of treatment procedures and complications registered in the study population $(\mathrm{N}=50)$

\begin{tabular}{|l|l|}
\hline Parameter & Summary \\
\hline Jaundice & \\
\hline Cachexia & $18(36 \%)$ \\
\hline Ascites & $20(40 \%)$ \\
\hline Liver secondaries & $24(48 \%)$ \\
\hline Anorexia & $12(24 \%)$ \\
\hline Goo & $5(10 \%)$ \\
\hline Cholangitis & $10(20 \%)$ \\
\hline Death & $5(10 \%)$ \\
\hline Treatment given & \\
\hline Surgery & $20(40 \%)$ \\
\hline Palliative treatment & $13(26 \%)$ \\
\hline Referral & $9(18 \%)$ \\
\hline Non-compliance & $8(16 \%)$ \\
\hline Treatment complications & \\
\hline Uneventful & $21(42 \%)$ \\
\hline Inoperability & $13(26 \%)$ \\
\hline Biliary gastritis & $6(12 \%)$ \\
\hline Wound infections & $7(14 \%)$ \\
\hline Death & $3(6 \%)$ \\
\hline
\end{tabular}

\section{Discussions}

This descriptive cross-sectional study was conducted with an aim to evaluate the clinical spectrum of obstructive jaundice in inflammation, stone disease, and malignancy. The principal findings of this study showed that obstructive jaundice occurred most commonly in elderly males, and the most common cause of obstructive was a malignancy. Surgical management played an important role in the study participants. The post-surgical outcome was uneventful.

According to this current study, the most commonly affected age group was 51 to 70 years. Based on this finding, obstructive jaundice can be considered as a disease of the elderly age group. Males were more frequently affected compared to females. These findings were similar to the study by Verma et al. [13], where the most commonly affected age group was 50 to 60 years, and males were affected more. The most common presenting complaint of the obstructive jaundice patient was jaundice, i.e., yellowish discoloration followed by vomiting and abdominal pain. Similar findings of the presentation were observed in a study by Siddique et al. [14], wherein benign obstructive jaundice the most common presentation was yellowish discoloration and abdominal pain. The abdominal distension was present in a few of the participants, which can be attributed to the ascites caused due to the malignant etiology. Due to the deposition of bile salts and pigments in the nerve endings, few participants had complaints of itching. The management of itching was 
done by bile acid sequestrant cholestyramine. In this study, $60 \%$ of the participants had malignant etiology to obstructive jaundice, relatively similar to the study of Siddique et al. [14] where malignancy was present in $56.6 \%$ of the study participants. The ultrasonography revealed majority of the cases had CBD dilatation and growth. Ultrasonography is the procedure of choice for the diagnosis of the dilated biliary system, able to identify the level of obstruction, that is, either intrahepatic or extra hepatic [15].

Assi et al. suggest that ultrasonography should be the first diagnostic procedure that has to be done on a patient with features suggestive of obstructive jaundice [2]. Among the participants, $40 \%$ were treated by surgical interventions. Choledocholithotomy and choledochoduodenostomy was the common procedure performed. The majority had an uneventful postoperative period and recovered well.

The limitation of the current study was that it was done on relatively small sample size. Accordingly, large multicentric studies on a wide population should provide in-depth knowledge on the various features and spectrum of obstructive jaundice.

\section{Conclusions}

The etiology of obstructive jaundice was malignancy in the elderly male population. The most common presenting features were yellowish discoloration of skin and mucosa, followed by vomiting and abdominal pain. Ultrasound plays an important role in the early diagnosis of the condition and specifies the location of the cause of obstruction. This study concludes that early identification using ultrasound and appropriate surgical management of obstructive jaundice will ensure a good clinical outcome, reducing mortality and morbidity.

\section{Conflict of interest disclosure}

There are no known conflicts of interest in the publication of this article. The manuscript was read and approved by all authors.

\section{Compliance with ethical standards}

Any aspect of the work covered in this manuscript has been conducted with the ethical approval of all relevant bodies and that such approvals are acknowledged within the manuscript.

\section{Acknowledgments}

We acknowledge the technical support in data entry, analysis, and manuscript editing by "Evidencian Research Associates."

\section{References}

1. Ralston S, Penman I, Strachan M, Hobson R. Davidson's principles and practice of medicine. $23 \mathrm{rd}$ Edition, Edinburgh, Churchill: Elsevier; 2018. 1440 p. ISBN: 9780702070273, Available from: https://www.elsevier.com/books/davidsons-principlesand-practice-of-medicine/ralston/978-0-7020-7028-0

2. Assi AN, Hassan AJ, Ali NK. The Etiological Spectrum of Obstructive Jaundice \& Role of Ercp In Thi-Qar Governorate. IOSR J Pharm. 2013;3(3):26-30.

3. Sharma MP, Ahuja V. Aetiological spectrum of obstructive jaundice and diagnostic ability of ultrasonography: a clinician's perspective. Trop Gastroenterol. 1999;20(4):167-9.

4. Acalovschi M. Cholangiocarcinoma: risk factors, diagnosis and management. Rom J Intern Med. 2004;42(1):41-58.

5. Bruno MS, Ober WB. Clinicopathologic conference. Obstructive jaundice. Case presentation. N Y State J Med. 1977;77(11):1745-51.

6. Bekele Z, Yifru A. Obstructive jaundice in adult Ethiopians in a referral hospital. Ethiop Med J. 2000;38(4):267-75.

7. Gaduputi V, Ippili R, Sakam S, Tariq H, Niazi M, Rahnemai-Azar AA, Chilimuri S. Extrahepatic biliary obstruction: an unusual presentation of hepatic sarcoidosis. Clin Med Insights Gastroenterol. 2015;8:19-22. doi: 10.4137/CGast.S22809

8. Hayat JO, Loew CJ, Asrress KN, McIntyre AS, Gorard DA. Contrasting liver function test patterns in obstructive jaundice due to biliary strictures [corrected] and stones. QJM. 2005;98(1):35-40. doi: 10.1093/qjmed/hci004

9. Chalya PL, Kanumba ES, McHembe M. Etiological spectrum and treatment outcome of Obstructive jaundice at a University teaching Hospital in northwestern Tanzania: A diagnostic and therapeutic challenges. BMC Res Notes. 2011;4:147. doi: 10.1186/1756-0500-4-147

10. Inan I, Sirik M. Diagnostic value of the choledochal sphericity index in the diagnosis of obstructive cholestasis using magnetic resonance cholangiopancreatography. Acta Gastroenterol Belg. 2020;83(4):571-575.

11. Khurram M, Durrani AA, Hasan Z, Butt Au, Ashfaq S. Endoscopic retrograde cholangiopancreatographic evaluation of patients with obstructive jaundice. J Coll Physicians Surg Pak. 2003;13(6):325-8.

12. Howlader N, Noone AM, Krapcho M, Miller D, Bishop K AS. SEER Cancer Statistics Review 1975-2013 National Cancer Institute. SEER Cancer Stat Rev. 2016;79:19922013. https://seer.cancer.gov/csr/1975_2018/ 
13. Verma S, Sahai S, Gupta P, Munshi A, Verma S, Goyal P. Obstructive Jaundice- Aetiological Spectrum, Clinical, Biochemical And Radiological Evaluation At A Tertiary Care Teaching Hospital. The Internet J Trop Med. 2010;7(2):1-8.

14. Siddique K, Ali Q, Mirza S, Jamil A, Ehsan A, Latif S, Malik AZ. Evaluation of the aetiological spectrum of obstructive jaundice. J Ayub Med Coll Abbottabad. 2008;20(4):62-6.
15. Ramirez DA, Dawoud SA, Simmons BA, Silverman WB, Shriver EM. Biliary obstruction-induced coagulopathy with subperiosteal orbital hemorrhage after endoscopic retrograde cholangiopancreatography. Can J Ophthalmol. 2021:S0008-4182(21)00122-8. doi: 10.1016/j.jcjo.2021.03.010 